\title{
Comparative Oncological Outcomes Following Radical Prostatectomy or External Beam Radiation Therapy Plus Androgen Deprivation Therapy in Men with Clinical T3b Prostate Cancer
}

\section{Wonchul Lee}

Hallym University Dongtan Sacred Heart Hospital

Bumjin Lim

Asan Medical Center

Yoon Soo Kyung

Asan Medical Center

Choung-Soo Kim ( $\nabla$ cskim@amc.seoul.kr)

University of Ulsan College of Medicine https://orcid.org/0000-0002-7464-3207

\section{Research Article}

Keywords: Radical Prostatectomy, External beam radiation therapy, cancer-specific survival

Posted Date: April 30th, 2021

DOI: https://doi.org/10.21203/rs.3.rs-442343/v1

License: (a) (1) This work is licensed under a Creative Commons Attribution 4.0 International License. Read Full License 


\section{Abstract}

Purpose To compare oncological outcomes in men with clinical T3b prostate cancer who underwent radical prostatectomy (RP) or a combination of radiation therapy plus androgen deprivation therapy $(\mathrm{HT}+$ $\mathrm{RT})$.

Materials and Methods Men with clinical T3b prostate cancer who underwent RP or HT + RT between 2007 and 2014 were evaluated. All patients were relatively healthy, with Eastern Cooperative Oncology Group (ECOG) performance status of 0 or 1 without nodal or distant metastasis. Cancer-specific survival (CSS) was analyzed. Age, biopsy Gleason score, and initial prostate specific antigen (PSA) concentration were adjusted by propensity score matching. Cox proportional hazard model was used to assess factors prognostic of CSS.

Results Of the 152 patients with clinical T3b prostate cancer, 45 underwent RP and 107 underwent HT + RT between 2007 and 2014. Mean CSS was significantly longer in the RP than in the HT + RT group ( $p=$ 0.029). Age, biopsy Gleason score, and pretreatment PSA concentration were significantly higher in the HT + RT group. In the propensity score matched population of 34 patients each, CSS remained significantly longer in the RP than in the HT + RT group (125.21 \pm 5.10 months vs. $107.73 \pm 9.01$ months, $p=0.041)$. Multivariate analysis showed that undergoing $\mathrm{HT}+\mathrm{RT}$ was the only significant poor prognostic factor for CSS (hazard ratio $=2.849 ; 95 \%$ confidence interval, $1.086-7.473, p=0.033$ ).

Conclusion CSS was significantly longer in men with clinical T3b prostate cancer who underwent RP than $H T+R T$, suggesting that RP should be the initial treatment of choice for these patients.

\section{Introduction}

Prostate cancer (PC) is the most common cancer in men and the second leading cause of male cancer deaths in Western countries (Jemal et al. 2006). PC is most frequently diagnosed in men aged 60-70 years, with most new cancers localized to the prostate gland (Xylinas et al. 2009). Definitive treatments of organ confined PC include radical prostatectomy (RP) and external beam radiation therapy (EBRT) (Bagshaw et al. 1994; Epstein et al. 1996; Gerber et al. 1996; Perez et al. 1993), although the lack of definite and well-conducted randomized controlled trials have made the optimal therapy for prostate tumors unclear (Arcangeli et al. 2009). RP is recommended for patients who are younger and healthier without tumor fixation to the pelvic sidewall.

However, there are no precise criteria to decide definitive treatment and no definitive evidence to determine which management provides better outcomes to patients. Current clinical guidelines suggest that either treatment is suitable, with the difficult treatment dicision for patients with tumors at high or very-high risk. Information from retrospective studies is therefore needed to determine the best treatment options for patients with high or very high risk PCs (Arcangeli et al. 2009; Boorjian et al. 2011; Zelefsky et al. 2010). In the present study, we focused on treatment options in men with cT3b PC categorized as being at very-high 
risk. Cancer-specific survival (CSS) was compared in men with cT3b PC who underwent RP or EBRT plus androgen deprivation therapy (HT+RT).

\section{Materials And Methods}

\section{Patient Population}

This study retrospectively analyzed 152 Korean men with cT3b PC without nodal or distant metastasis, including 45 (29.6\%) who underwent RP and 107 (70.4\%) who underwent HT+RT, from August 1999 to December 2014. Patients with other malignancies were excluded.

\section{Patient Evaluation}

All patients were examined by chest X-rays, abdomino-pelvic computed tomography (CT), pelvic magnetic resonance imaging (MRI), and whole-body bone scintigraphy to determine the clinical stage of PC.

Prostate volume was measured by trans-rectal ultrasonography. cT3b was defined as seminal vesicle (SV) involvement, evaluated on T1- or T2-weighted multiparametric MRI images. SV invasion on T2-weighted MRI images was defined as the disruption or absence of the normal appearance of the SV, focal or diffuse areas of low signal intensity within the SV, low signal intensity within the SV causing a mass effect, or direct extension of the low signal intensity of a tumor from the base of the prostate to the SV. Dynamic T1weighted images showing enhancing lesions on the SV wall were defined as SV invasion (Kim et al. 2008; Yamamoto et al. 2014).

\section{Radical Prostatectomy}

Of the 45 patients who underwent RP, 17 (37.8\%) underwent robot assisted RP and 28 (62.2\%) underwent open RP. Of these 45 patients, $43(95.6 \%)$ also underwent pelvic lymph node dissection (PLND), including extended PLND in 21 patients (46.7\%). Thirty-three patients (75.6\%) received neoadjuvant androgen deprivation therapy (ADT) for a median 1.25 months (range: 0.1-4.7 months) before surgery. The choice to administer neoadjuvant ADT was at each physician's discretion. At last follow-up, $29(64.4 \%)$ of the 45 patients had received adjuvant or salvage ADT, and 15 patients (33.3\%) had received adjuvant or salvage EBRT of 66 Gy or 72.6 Gy due to PSA failure or adverse pathological features, such as lymph node metastasis or SV invasion.

\section{External Beam Radiation Therapy and Androgen Deprivation Therapy}

In our institution, high-risk or very high-risk PC patients received dose escalated whole pelvic radiation therapy (Joo et al. 2013). Intensity modulated radiotherapy and image guidance were used to reduce the toxicities related to radiation therapy. The gross target volume included the entire prostate and the involved lymph nodes. The clinical target volume included the gross target volume, SVs, and the internal iliac, external iliac, and obturator nodal regions. The planning target volume was 5-7 mm wider than the clinical target volume. The doses and fractionation plans were modified in 2011 in our institute. Before 2011, the whole pelvis and boost doses were $46 \mathrm{~Gy}$ and $76 \mathrm{~Gy}$, respectively, administered in $2 \mathrm{~Gy}$ fractions. After 
2011, the fraction size was increased to $2.2 \mathrm{~Gy}$, and the whole pelvis and boost doses were $44 \mathrm{~Gy}$ and 72.6 Gy, respectively.

Of the 152 patients who underwent RP or HT+RT, 140 (92.1\%) received neoadjuvant ADT prior to the definitive treatments, including five (3.6\%) receiving bicalutamide alone, 32 (22.9\%) receiving luteinizing hormone-releasing hormone agonist, and 103 (73.5\%) receiving maximal androgen blockade (MAB), consisting of a combination of luteinizing hormone-releasing hormone agonist and bicalutamide.

In the RP group, two patients(3.8\%) received neoadjuvant bicalutamide alone, 7patients(13.5\%) received luteinizing hormone-releasing hormone agonist alone and 24patients(46.2\%) received MAB. Of the 107 patients who underwent $\mathrm{HT}+\mathrm{RT}, 18$ patients (16.8\%) received neoadjuvant bicalutamide alone, 24 (22.4\%) received luteinizing hormone-releasing hormone agonist alone, and $65(60.7 \%)$ received MAB. ADT was administered to patients in the HT+RT group for a mean $40.08 \pm 35.90$ months.

\section{Statistical Analysis}

Categorical variables in the HT+RT and RP groups were compared using Pearson's Chi-square tests, and continuous variables were compared using Student's t-tests. CSS was determined using the Kaplan-Meier method and compared using log-rank tests. Multivariate analyses Cox proportional hazard analysis was performed to assess factors predictive of CSS. One-to-one propensity score matching was performed to determine the effects of each treatment method. Propensity scores were calculated by multivariable logistic regression analysis, with age, body mass index, Eastern Cooperative Oncology Group (ECOG) Performance Status, prostate volume, initial prostate specific antigen (PSA) concentration, and biopsy Gleason score (GS) being the matched covariates. Standardized differences below 0.2 were considered well balanced. All statistical analyses were performed using SPSS ver. 25.0.

\section{Results}

The study cohort consisted of 152 Korean men with cT3b PC without nodal or distant metastasis, including 107 patients (70.4\%) who received HT+RT and 45 (29.6\%) who underwent RP. The mean followup duration was $62.94 \pm 40.86$ months. Table 1 shows the baseline characteristics of the overall population and of the propensity score matched population of 34 patients in each group. Mean ages of patients in the RP and HT+RT groups were $67.53 \pm 6.08$ years and $73.71 \pm 6.45$ years, respectively; and mean pretreatment PSA concentrations were $17.1 \pm 13.97 \mathrm{ng} / \mathrm{mL}$ and $47.18 \pm 56.91 \mathrm{ng} / \mathrm{mL}$, respectively. Biopsy GS was significantly higher in the HT+RT group ( $p=0.035)$. Propensity score matching yielded 34 patients in each group, well matched in age (69.62 \pm 4.93 years vs. $70.32 \pm 5.79)$, pretreatment PSA concentration $(18.41 \pm 15.37 \mathrm{ng} / \mathrm{mL}$ vs. $18.6 \pm 18.65 \mathrm{ng} / \mathrm{mL})$, and biopsy GS.

Figure 1 shows the CSS of each group in the overall population. 5-yr and 10-yr CSS rate was significantly higher in the RP group than the HT+RT group (100\% vs $89 \%, 87 \%$ vs $73 \%$, respectively, $\mathrm{p}=0.029$ ). Following propensity score matching, median CSS was significantly longer in the RP than in the HT+RT group (125.21 \pm 5.10 months vs. $107.73 \pm 9.01$ months $(p=0.041$; Figure 2$)$ ). 
Univariate analysis of factors prognostic for CSS showed that type of treatment $(p=0.012)$ and biopsy GS $(p=0.039)$ were significantly associated with CSS (Table 2$)$, whereas multivariate analysis showed that treatment type was the only factor significantly prognostic of CSS (hazard ratio, $2.849 ; 95 \% \mathrm{Cl}, 1.086-$ $7.473, p=0.033)$.

The pathological results of patients who underwent RP are shown in Table 3. Of the 45 specimens, 26 (57.8\%) had GS higher than 8 . Twenty-one (46.7\%) patients showed consistency between clinical T stage and pathological T stage. In addition, six patients (13.3\%) had nodal metastasis and $30(66.7 \%)$ had positive surgical margin. Twenty-nine patients (64.4\%) experienced biochemical recurrence(BCR), which required subsequent ADT. Eight patients (27.6\%) received adjuvant RT and seven (24.1\%) received salvage RT.

\section{Discussion}

Although PSA screening has resulted in the earlier detection of PC (Ward et al. 2005; Xylinas et al. 2009), some patients have high-risk disease at the time of diagnosis. In a study done by Arcangeli, G., et al., RP has shown improved oncological outcomes in patients with high-risk PC when compared with EBRT (Arcangeli et al. 2009). This was considered due to the lack of adequate balance of other prognostic factors, such as pretreatment PSA concentration and clinical T stage. Indeed, when appropriately balanced, disease outcomes were similar in patients who received RP and EBRT. By contrast, our study showed that CSS was significantly longer in the RP than in the HT+RT group, even after adjusting for age, pretreatment PSA concentration, clinical T stage, and biopsy GS.

According to NCCN guidelines, surgery is not generally recommended in patients with low or intermediate risk PC and an estimated life expectancy of $<10$ years (Carroll and Mohler 2018). Results from the Surveillance, Epidemiology, and End Results (SEER) database indicated that survival outcomes in patients with an estimated life expectancy of $\geq 10$ years at diagnosis were superior with RP than with EBRT or observation (Sun et al. 2014). By contrast, both RP and HT+RT are proper management techniques in patients with high or very high risk PC and an estimated life expectancy of $>5 \mathrm{yrs}$. The results of the CaPSURE study showed that most high-risk PC patients underwent HT+RT, with only about $36 \%$ initially treated with RP (Meng et al. 2005). The percentage of patients receiving RP as initial treatment may be even lower in patients with SV invasion, defined as cT3b PC. In this study, only $29.6 \%$ of patients with cT3b PC underwent RP.

The optimal management of clinically advanced localized PC remains unclear due to the lack of conclusive, well-designed randomized trials (Hakenberg et al. 2006). A prospective randomized trial comparing oncological outcomes in PC patients receiving ADT plus RP and HT+RT found that both approaches yielded favorable long-term outcomes (Akakura et al. 2006). However, this study included patients with clinical T2b PCs, which are considered intermediate risk, confusing the determination of optimal therapy in patients with high or very high risk PC. Cancer-specific mortality in patients with cT3NO$1 \mathrm{PC}$ was shown to be significantly lower after RP than after EBRT, but, because that study used the SEER 
database, information on ADT and chemotherapy was lacking (Bandini et al. 2018). Therefore, despite it being a large scale study, the relative advantages of RP and EBRT could not be determined.

Ward et al. (2005) reported that among the patients with cT3 PC, $27 \%$ of patients turned out to be pT2 disease after RP. They concluded that RP might potentially cure $27 \%$ of patients who were overstaged. Similarly, Carver et al. (2006) demonstrated their results about treatment outcomes of 176 patients with CT3 PC and they reported that $24 \%$ of patients were pathologically downstaged to pT2. The pathological results of patients who underwent RP in our study demonstrated that $46.7 \%$ had pT3b disease which means that more than half of the patients were downstaged regarding the T stage. $20 \%$ of patients were downstaged to pT2. These results suggest that RP should be the initial treatment recommendation when cT3b PCs are encountered at the time of clinical diagonosis.

Hsu et al. (2010) reported that the 10-year CSS rates of 164 men with cT3 PC who underwent RP was $80 \%$. In our study, the 5 -year CSS rate in RP group was $100 \%$ and 10 -year CSS rate was $87 \%$. These findings demonstrate that RP as an initial treatment in cT3b patients were reasonable.

Yamamoto S.et al. (2014) demonstrated that cT3b stage was a very strong predictive factors of local progression and CSS. They reported that CT3b PC had significantly poor prognosis regardless of type of initial treatment. Joniau et al. (2012) reported the 10-year clinical progression free survival and CSS rates of 51 patients with cT3b-4 treated with RP which were 73 and $92 \%$ respectively. Zelefsky et al. (2010) reported that the 10-year CSS of CT3b patients treated with EBRT plus in conjunction with neoadjuvant and concurrent ADT was $61 \%$. The oncological outcomes were significantly worse in cT3b PC than that of cT3a PC patients. In our study, the 10-year CSS of cT3b PC patients treated with HT+RT was 73\%. Based on these results, the development of effective adjuvant treatment after definitive treatment is urgently needed for cT3b PC patients

Our study demonstrated that RP yielded longer CSS than HT+RT in men with cT3b PC. Data on patients were precise, including type and duration of ADT, and dose and duration of EBRT. Because age, pretreatment PSA concentration, and biopsy GS were significantly higher in the HT+RT group, variables were adjusted by propensity score matching, minimizing selection bias. Baseline characteristics in the 34 pairs of propensity matched patients did not differ significantly. Even after propensity score match, CSS was significantly longer in the RP than in the HT+RT group, a finding supported by multivariate Cox proportional hazard analysis, which found that treatment with HT+RT increased the likelihood of cancerspecific death 2.849-fold compared with treatment with RP. To the best of our knowledge, there are only a few studies which analyzed and compared survival outcomes of RP and EBRT in men with cT3b PC. The patient data were of high quality, with almost no missing clinical and pathological information. Our study results may give additional supportive evidence to previous studies that RP is an optimal treatment options in cT3b PC.

This study had several limitations. First, the size of the total cohort was quite small, and few patients were available for propensity score matching, limiting precise statistical assessment. Second, due to its retrospective design, this study may have had selection bias. Third, treatment-related toxicity could not be 
determined. Treatment-related toxicity is important when deciding the best treatment option for each patient. Further studies should include treatment-related toxicity for better comparison between the two treatment options. Lastly, ADT and EBRT differed in the HT+RT group. The RT protocol changed in 2011 in our institution and ADT protocols differed among patients. Larger cohort studies and randomized controlled trials are needed to confirm these results.

In conclusion, RP should be recommended as the initial treatment option for men with cT3b PC. Other treatments may be more sui table after biochemical recurrence or treatment failure.

\section{Declarations}

\section{Funding}

This research did not receive any specific funding from the public, commercial, or notfor profit sectors.

\section{Conflicts of interest}

None

\section{Ethics approval}

The requirement for patient informed consent was waived by the Institutional Review

Board of Asan Medical Center

\section{Consent to participate / Consent for publication}

All patients whose data were retrospectively analyzed were informed of the use of their clinical information under anonymization and received an opportunity to object to use or publication.

\section{Availability of data and material}

Available from corresponding author upon reasonable request.

\section{Code availability}

Not applicable.

\section{Author's contributions:}

Study conception and design-Wonchul Lee, Choung-Soo Kim

Data acquisition- Bumjin Lim, Yoon Soo Kyung 
Data analysis and interpretation- Wonchul Lee, Bumjin Lim

Manuscript drafting- Wonchul Lee

Critical manuscript revisions- Yoon Soo Kyung

Supervision- Choung-Soo Kim

\section{References}

Akakura K, Suzuki H, Ichikawa T, Fujimoto H, Maeda O, Usami M, Hirano D, Takimoto Y, Kamoto T, Ogawa O, Sumiyoshi Y, Shimazaki J, Kakizoe T (2006) A randomized trial comparing radical prostatectomy plus endocrine therapy versus external beam radiotherapy plus endocrine therapy for locally advanced prostate cancer: results at median follow-up of 102 months. Jpn J Clin Oncol 36:789-793.

https://doi.org/10.1093/jjco/hyl115

Arcangeli G, Strigari L, Arcangeli S, Petrongari MG, Saracino B, Gomellini S, Papalia R, Simone G, De Carli P, Gallucci M (2009) Retrospective comparison of external beam radiotherapy and radical prostatectomy in high-risk, clinically localized prostate cancer. Int J Radiat Oncol Biol Phys 75:975-982.

https://doi.org/10.1016/j.jijrobp.2008.12.045

Bagshaw MA, Cox RS, Hancock SL (1994) Control of prostate cancer with radiotherapy: long-term results. J Urol 152:1781-1785. https://doi.org/10.1016/s0022-5347(17)32385-6

Bandini M, Marchioni M, Preisser F, Zaffuto E, Tian Z, Tilki D, Montorsi F, Shariat SF, Saad F, Briganti A, Karakiewicz PI (2018) Survival after radical prostatectomy or radiotherapy for locally advanced (cT3) prostate cancer. World J Urol 36:1399-1407. https://doi.org/10.1007/s00345-018-2310-y

Boorjian SA, Karnes RJ, Viterbo R, Rangel LJ, Bergstralh EJ, Horwitz EM, Blute ML, Buyyounouski MK (2011) Long-term survival after radical prostatectomy versus external-beam radiotherapy for patients with high-risk prostate cancer. Cancer 117:2883-2891. https://doi.org/10.1002/cncr.25900

Carroll PH, Mohler JL (2018) NCCN guidelines updates: prostate cancer and prostate cancer early detection. J Natl Compr Canc Netw 16:620-623. https://doi.org/10.6004/jnccn.2018.0036

Carver BS, Bianco FJ, Jr., Scardino PT, Eastham JA (2006) Long-term outcome following radical prostatectomy in men with clinical stage T3 prostate cancer. J Urol 176:564-568.

https://doi.org/10.1016/j.juro.2006.03.093

Epstein JI, Partin AW, Sauvageot J, Walsh PC (1996) Prediction of progression following radical prostatectomy: a multivariate analysis of 721 men with long-term follow-up. Am J Surg Pathol 20:286-292. https://doi.org/10.1097/00000478-199603000-00004 
Gerber GS, Thisted RA, Scardino PT, Frohmuller HG, Schroeder FH, Paulson DF, Middleton AW, Jr., Rukstalis DB, Smith JA, Jr., Schellhammer PF, Ohori M, Chodak GW (1996) Results of radical prostatectomy in men with clinically localized prostate cancer. JAMA 276:615-619

Hakenberg OW, Frohner M, Wirth MP (2006) Treatment of locally advanced prostate cancer: the case for radical prostatectomy. Urol Int 77:193-199. https://doi.org/10.1159/000094808

Hsu CY, Wildhagen MF, Van Poppel H, Bangma CH (2010) Prognostic factors for and outcome of locally advanced prostate cancer after radical prostatectomy. BJU Int 105:1536-1540.

https://doi.org/10.1111/j.1464-410X.2009.09054.x

Jemal A, Siegel R, Ward E, Murray T, Xu J, Smigal C, Thun MJ (2006) Cancer statistics, 2006. CA Cancer J Clin 56:106-130. https://doi.org/10.3322/canjclin.56.2.106

Joniau S, Hsu CY, Gontero P, Spahn M, Van Poppel H (2012) Radical prostatectomy in very high-risk localized prostate cancer: long-term outcomes and outcome predictors. Scand J Urol Nephrol 46:164-171. https://doi.org/10.3109/00365599.2011.637956

Joo JH, Kim YJ, Kim YS, Choi EK, Kim JH, Lee SW, Song SY, Yoon SM, Kim SS, Park JH, Jeong Y, Ahn H, Kim CS, Lee JL, Ahn SD (2013) Whole pelvic intensity-modulated radiotherapy for high-risk prostate cancer: a preliminary report. Radiat Oncol J 31:199-205. https://doi.org/10.3857/roj.2013.31.4.199

Kim CK, Choi D, Park BK, Kwon GY, Lim HK (2008) Diffusion-weighted MR imaging for the evaluation of seminal vesicle invasion in prostate cancer: initial results. J Magn Reson Imaging 28:963-969. https://doi.org/10.1002/jmri.21531

Meng MV, Elkin EP, Latini DM, Duchane J, Carroll PR (2005) Treatment of patients with high risk localized prostate cancer: results from cancer of the prostate strategic urological research endeavor (CaPSURE). J Urol 173:1557-1561. https://doi.org/10.1097/01.ju.0000154610.81916.81

Perez CA, Hanks GE, Leibel SA, Zietman AL, Fuks Z, Lee WR (1993) Localized carcinoma of the prostate (stages T1B, T1C, T2, and T3). Review of management with external beam radiation therapy. Cancer 72:3156-3173. https://doi.org/10.1002/1097-0142(19931201)72:11<3156::aid-cncr2820721106>3.0.co;2g

Sun M, Sammon JD, Becker A, Roghmann F, Tian Z, Kim SP, Larouche A, Abdollah F, Hu JC, Karakiewicz PI, Trinh QD (2014) Radical prostatectomy vs radiotherapy vs observation among older patients with clinically localized prostate cancer: a comparative effectiveness evaluation. BJU Int 113:200-208. https://doi.org/10.1111/bju.12321

Ward JF, Slezak JM, Blute ML, Bergstralh EJ, Zincke H (2005) Radical prostatectomy for clinically advanced (cT3) prostate cancer since the advent of prostate-specific antigen testing: 15-year outcome. BJU Int 95:751-756. https://doi.org/10.1111/j.1464-410X.2005.05394.x 
Xylinas E, Drouin SJ, Comperat E, Vaessen C, Renard-Penna R, Misrai V, Bitker MO, Chartier-Kastler E, Richard F, Cussenot O, Roupret M (2009) Oncological control after radical prostatectomy in men with clinical T3 prostate cancer: a single-centre experience. BJU Int 103:1173-1178.

https://doi.org/10.1111/j.1464-410X.2008.08208.x

Yamamoto S, Kawakami S, Yonese J, Fujii Y, Urakami S, Kitsukawa S, Masuda H, Ishikawa Y, Kozuka T, Oguchi M, Kohno A, Fukui I (2014) Long-term oncological outcome in men with T3 prostate cancer: radical prostatectomy versus external-beam radiation therapy at a single institution. Int J Clin Oncol 19:10851091. https://doi.org/10.1007/s10147-013-0654-2

Zelefsky MJ, Eastham JA, Cronin AM, Fuks Z, Zhang Z, Yamada Y, Vickers A, Scardino PT (2010) Metastasis after radical prostatectomy or external beam radiotherapy for patients with clinically localized prostate cancer: a comparison of clinical cohorts adjusted for case mix. J Clin Oncol 28:1508-1513. https://doi.org/10.1200/JC0.2009.22.2265

\section{Tables}

Table 1. Baseline characteristics of the overall population and the propensity score matched population

\begin{tabular}{|c|c|c|c|c|c|c|c|}
\hline & \multicolumn{4}{|c|}{ Overall population } & \multicolumn{3}{|c|}{ Propensity matched population } \\
\hline & $\mathrm{RP}$ & $\mathrm{HT}+\mathrm{RT}$ & \multirow{2}{*}{$\begin{array}{l}\mathrm{P} \\
\text { value }\end{array}$} & \multirow{2}{*}{$\begin{array}{l}\text { Std } \\
\text { diff }\end{array}$} & $\mathrm{RP}$ & $\mathrm{HT}+\mathrm{RT}$ & \multirow{2}{*}{$\begin{array}{l}\text { Std } \\
\text { diff }\end{array}$} \\
\hline & $(n=45)$ & $(n=107)$ & & & $(n=34)$ & $(n=34)$ & \\
\hline Age, yr & $67.53 \pm 6.08$ & $73.71 \pm 6.45$ & $<0.001$ & 0.985 & $69.62 \pm 4.93$ & $70.32 \pm 5.79$ & 0.131 \\
\hline $\mathrm{BMI}, \mathrm{kg} / \mathrm{m}^{2}$ & $23.95 \pm 2.48$ & $23.13 \pm 2.96$ & 0.114 & 0.302 & $24.18 \pm 2.33$ & $24.55 \pm 2.64$ & 0.150 \\
\hline $\begin{array}{l}\text { ECOG } \\
\text { performance } \\
\text { status, } \mathrm{n}(\%)\end{array}$ & & & 0.162 & 0.241 & & & 0.113 \\
\hline 0 & $5(11.11)$ & $5(4.67)$ & & & $3(8.82)$ & $2(5.88)$ & \\
\hline 1 & $40(88.89)$ & $102(95.33)$ & & & 31 (91.18) & $32(94.12)$ & \\
\hline $\begin{array}{l}\text { Prostate } \\
\text { volume, cc }\end{array}$ & $39.39 \pm 27.8$ & $40.35 \pm 24.15$ & 0.639 & 0.037 & $40.77 \pm 30.36$ & $42.06 \pm 21.4$ & 0.049 \\
\hline $\begin{array}{l}\text { Pretreatment } \\
\mathrm{PSA}, \mathrm{ng} / \mathrm{mL}\end{array}$ & $17.1 \pm 13.97$ & $47.18 \pm 56.91$ & $<0.001$ & 0.726 & $18.41 \pm 15.37$ & $18.6 \pm 18.65$ & 0.011 \\
\hline $\begin{array}{l}\text { Biopsy GS, n } \\
(\%)\end{array}$ & & & 0.035 & 0.491 & & & 0.150 \\
\hline$\leq 7$ & $18(40.91)$ & $24(22.43)$ & & & $16(47.06)$ & $13(38.24)$ & \\
\hline 8 & $13(29.55)$ & $30(28.04)$ & & & $8(23.53)$ & $10(29.41)$ & \\
\hline$\geq 9$ & $13(29.55)$ & $53(49.53)$ & & & $10(29.41)$ & $11(32.35)$ & \\
\hline
\end{tabular}


Std diff, standardized difference; BMI, body mass index; ECOG, Eastern Cooperative Oncology Group; PSA, prostate specific antigen; GS, Gleason score.

Table 2. Univariate and multivariate Cox proportional hazards analyses of factors significantly associated with cancer-specific survival

\begin{tabular}{|c|c|c|c|c|c|c|c|c|c|}
\hline & & $\begin{array}{l}\text { Hazard } \\
\text { ratio }\end{array}$ & $95 \% \mathrm{Cl}$ & & $\begin{array}{l}\mathrm{P} \\
\text { value }\end{array}$ & $\begin{array}{l}\text { Hazard } \\
\text { ratio }\end{array}$ & $\begin{array}{l}95 \% \\
\mathrm{Cl}\end{array}$ & & $\begin{array}{l}\mathrm{P} \\
\text { value }\end{array}$ \\
\hline $\begin{array}{l}\text { Treatment } \\
\text { group }\end{array}$ & $\mathrm{HT}+\mathrm{RT}$ & 3.028 & 1.278 & 7.175 & 0.012 & 2.849 & 1.086 & 7.473 & 0.033 \\
\hline Age & & 1.034 & 0.988 & 1.082 & 0.147 & 1.003 & 0.955 & 1.054 & 0.909 \\
\hline BMI & & 0.950 & 0.861 & 1.048 & 0.309 & & & & \\
\hline $\begin{array}{l}\text { ECOG } \\
\text { performance } \\
\text { status }\end{array}$ & 1 & Infinity & & & 0.985 & & & & \\
\hline $\begin{array}{l}\text { Prostate } \\
\text { volume }\end{array}$ & & 1.007 & 0.998 & 1.017 & 0.137 & & & & \\
\hline $\begin{array}{l}\text { Pretreatment } \\
\text { PSA }\end{array}$ & & 1.001 & 0.996 & 1.006 & 0.828 & 0.999 & 0.992 & 1.005 & 0.688 \\
\hline \multirow[t]{3}{*}{ Biopsy GS } & $\leq 7$ & 1 & & & 0.039 & 1 & & & 0.073 \\
\hline & 8 & 1.117 & 0.495 & 2.520 & 0.791 & 1.080 & 0.471 & 2.477 & 0.856 \\
\hline & $\geq 9$ & 2.305 & 1.082 & 4.913 & 0.031 & 2.111 & 0.980 & 4.544 & 0.056 \\
\hline
\end{tabular}

$\mathrm{Cl}$, confidence interval; ECOG, Eastern Cooperative Oncology Group; BMI, body mass index; PSA, prostate specific antigen; GS, Gleason score.

Table 3. Pathological outcomes in patients who underwent radical prostatectomy 


\begin{tabular}{|ll|}
\hline \multicolumn{2}{|l|}{$\mathrm{n}(\%)$} \\
Pathologic Gleason score & \\
$\geq 8$ & $15(33.3)$ \\
NA & $26(57.8)$ \\
\hline Pathologic T stage & $4(8.9)$ \\
T2 & \\
T3a & $9(20.0)$ \\
T3b & $12(26.7)$ \\
T4 & $21(46.7)$ \\
NA & $1(2.2)$ \\
Pathologic N stage & $2(4.4)$ \\
N0 & \\
N1 & $37(82.2)$ \\
NA & $6(13.3)$ \\
Positive surgical margin & $2(4.4)$ \\
Yes & \\
No & $30(66.7)$ \\
NA & $13(28.9)$ \\
Lymphovascular invasion & $2(4.4)$ \\
Yes & $22(48.9)$ \\
No & $21(46.7)$ \\
NA & $2(4.4)$ \\
Biochemical recurrence & \\
Nes & $1(2.2)$ \\
\hline
\end{tabular}

NA, not available.

Figures 


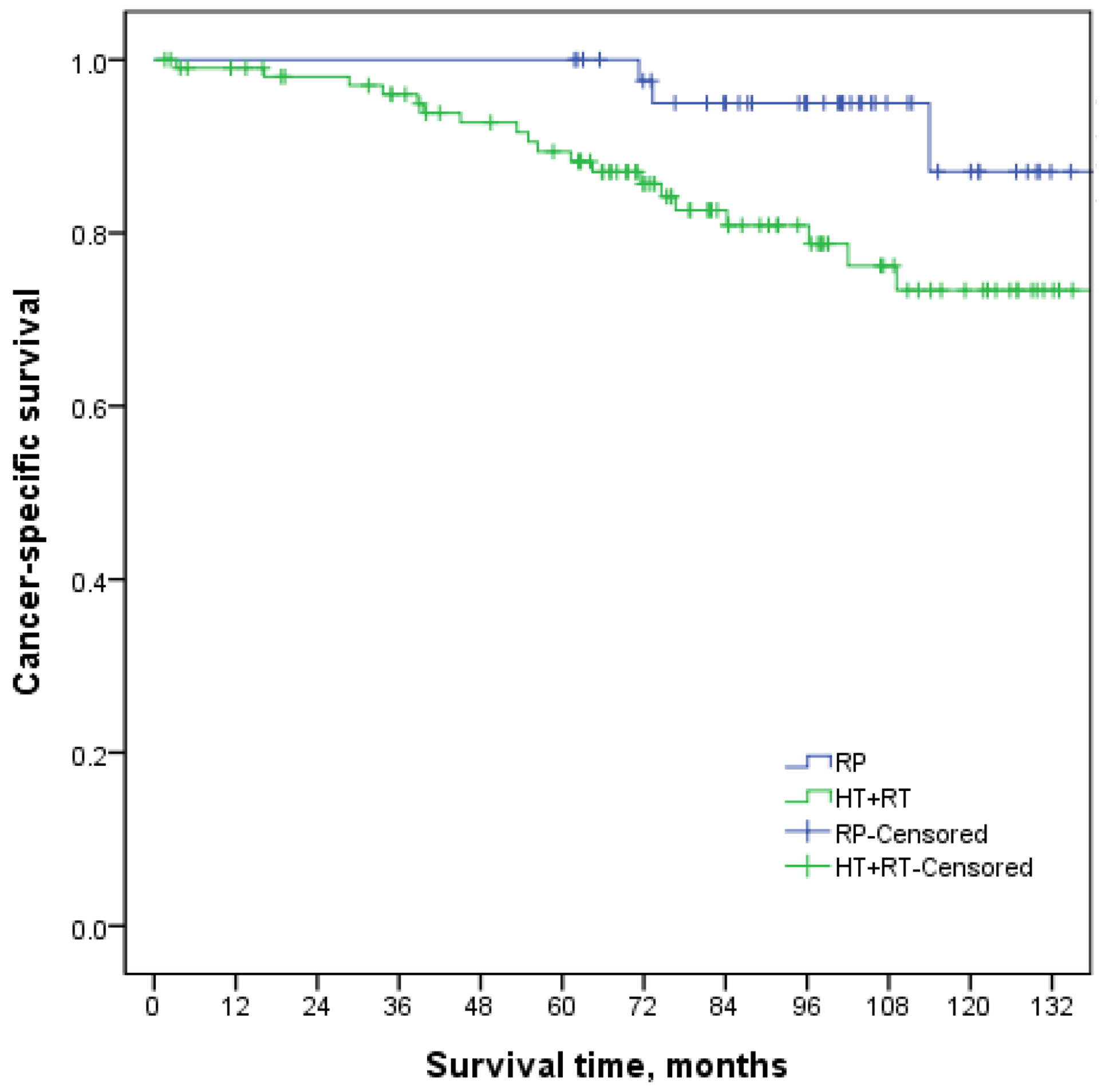

Figure 1

Kaplan-Meier analysis of cancer-specific survival in patients in the overall population who received RP and $H T+R T(p=0.029)$ 


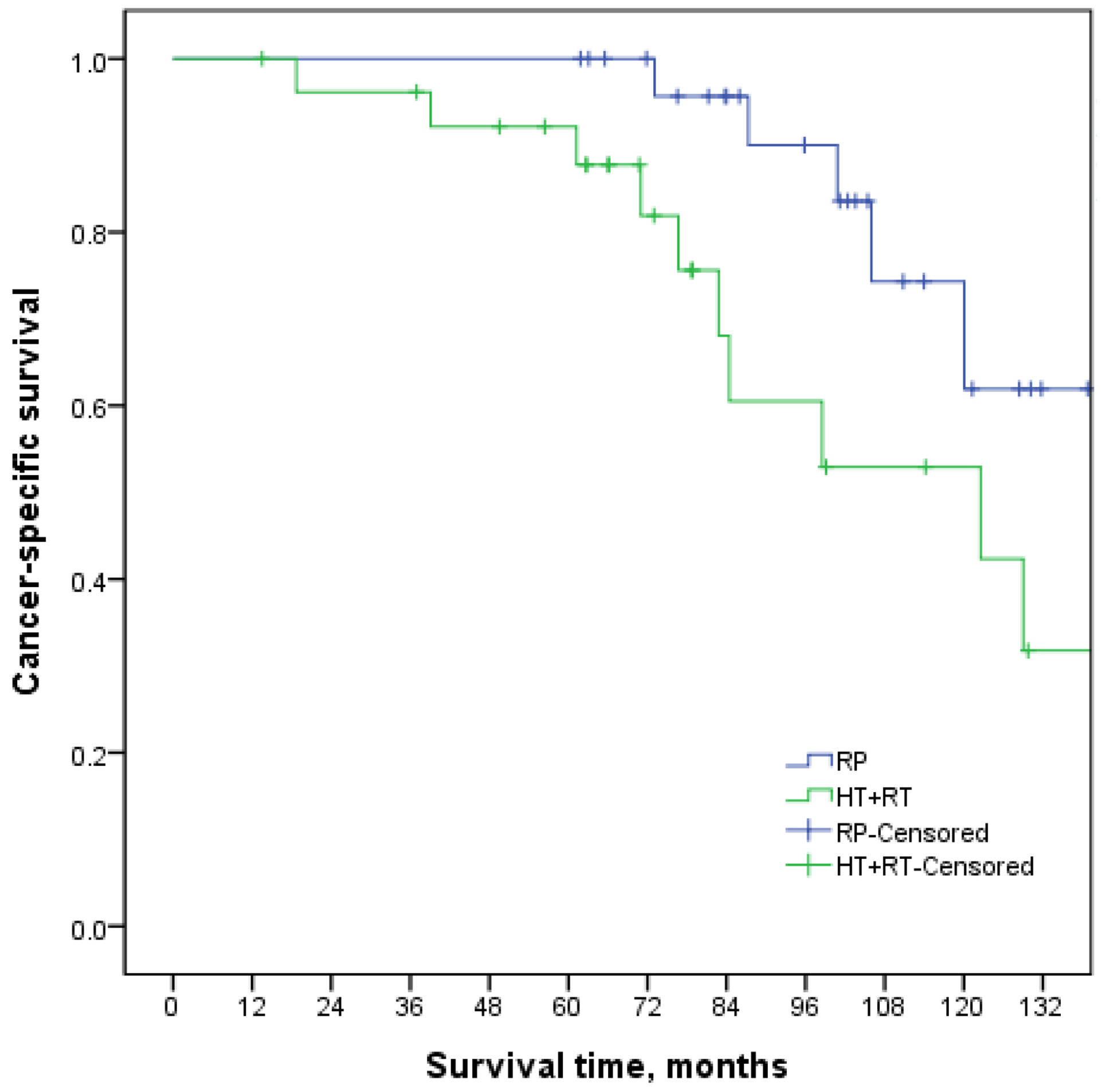

Figure 2

Kaplan-Meier analysis of cancer-specific survival in patients in the propensity matched population who received $R P$ and $H T+R T(p=0.041)$ 